\title{
ELEKTRONİK EKİPMAN KORUYUCU KUTUSUNUN EKRANLAMA ETKİNLİĞİ ANALİZi
}

Sunay G̈̈LER

Sibel YENIKAYA

Güneş YILMAZ

Öz: Emisyonları kısıtlayıcı yeni regülasyonlar neticesinde elektrikli araçlara olan talep gittikçe artmaktadır. Elektromanyetik uyumluluk (Electromagnetic Compatibility-EMC), yüksek gerilimli batarya ünitesi ve elektrikli sürüş sistemi bileşenlerinin konvansiyonel araç mimarisine dahil edilmesinden dolayı tasarım aşamasında değerlendirilmesi gereken en önemli konulardan biri haline gelmiştir. Bu çalışmada, elektrikli araçlarda sıklıkla karşılaşılan EMC problemlerinden biri olan elektronik ekipman koruyucu kutularındaki ekranlama problemi analiz edilmiştir. Açıklık ve kutu boyutları ile ekranlama etkinliğinin değişimi incelenmiş̧ir. Farklı açıklık geometrilerinin, ekranlama etkinliği üzerindeki etkisi 0-2 GHz aralığında nümerik olarak elde edilmiştir.

Anahtar Kelimeler: Otomotiv, Elektrikli araçlar, EMC, Ekranlama Etkinliği

\section{Shielding Effectiveness Analysis of Electronic Equipment Protection Box}

Abstract: Due to new regulations that limit emission, the demand for electric vehicles is being increased. Electromagnetic compatibility (EMC) has become one of the most important issues to be evaluated during design phase cause of incorporating high voltage battery unit and electric driving system components into conventional vehicle architecture. In this study, shielding problem of electronic equipment protection box, which is one of the most frequently observed EMC problems in electric vehicle is analyzed. The variation of shielding effeciency by changing aperture and enclosure dimensions is investigated. The effect of different aperture geometries on shielding effectiveness is obtained in the range of $0-2 \mathrm{GHz}$ numerically.

Keywords: Automotive, Electric vehicles, EMC, Shielding effectiveness

\footnotetext{
* TOFAŞ Türk Otomobil Fabrikası A.Ş. Arge Merkezi, DOSAB, İstanbul Cad. No:574, 16110, Osmangazi, Bursa

** Bursa Uludağ Üniversitesi, Mühendislik Fakültesi, Elektrik Elektronik Mühendisliği Bölümü, 16059, Bursa İletişim Yazarı: sunay.guler@tofas.com.tr
} 


\section{GİRIŞ}

Günümüz araç teknolojisinin her geçen gün daha çok elektronik ekipman ve sistemleri bünyesine dahil etmesi farklı elektromanyetik uyumluluk (EMC) problemlerinin de oluşmasına zemin hazırlamaktadır. Bu ekipman ve sistemlerin, araç içinde yer alan sistemlerden etkilenmemesi ve araç içi elektroniğini de etkilememesi için elektromanyetik ekranlama çalışmalarının yapılması gerekmektedir. Elektromanyetik ekranlama, elektronik ekipmanı çevresel elektromanyetik alan etkilerinden koruyan aynı zamanda çevreyi de ekipmanın yaydığı alan etkilerine karşı koruyan bir yapı olarak tanımlanmaktadır. Bu tip koruyucu yapıların tasarımında önemli bir parametre ise ekranlama etkinliği ya da verimliliğidir (Yenikaya ve Akman, 2009).

Ekranlama etkinliği (Shielding Effectiveness-SE) ile ilgili hem analitik hem de nümerik çözümler sunan birçok çalışma mevcuttur. Fiziksel yapı basit olduğu sürece bu tür problemlerin analitik yöntemler ile çözümü mümkünken, fiziksel yapı karmaşıklaştıkça EMC problemlerini çözmede nümerik yöntemlere olan ihtiyaç ortaya çıkmaktadır. Yazılım ve bilgisayar sektöründeki hızlı ilerleme, EMC problemlerinin sayısal yöntemlerle modellenerek çözümlenebilmesine olanak sağlamıştır. Analitik olarak çözülmesi zor, karmaşık yapıdaki EMC problemlerinin bilgisayar ortamında çözümlenebilmesi için birçok yöntem bulunmaktadır. Sonlu elemanlar yöntemi (FEM), zaman domeni sonlu farklar yöntemi (FDTD), iletim hattı matrisi yöntemi (TLM) ve moment yöntemi (MoM) en çok kullanılan ve üzerinde yoğun çalışmaların devam ettiği yöntemlerdir (Güler, 2007).

Belokour ve diğ. (2000) 0,1-1 GHz frekans aralığında, açıklıkların SE üzerinde etkilerini TLM ve FDTD yöntemlerini kullanarak karşılaştırmışlardır. Fan ve diğ. (2003) koruyucu kutu üzerindeki açıklığın uzunluğu ve genişliğine göre SE değişimini incelemek için FDTD yöntemini kullanılmışlardır. Açıklığın uzunluğu değiştiğinde rezonansın meydana geldiği gözlemlenmiştir. Feng ve diğ. (2005) FDTD ve MoM teknikleriyle hibrit bir yöntem oluşturarak, üzerinde açıklık bulunan dikdörtgen kutunun ekranlama etkinliğini hesaplamışlardır. Dan ve diğ. (2007) açıklık şekillerinin SE üzerindeki etkisini TLM ile hesaplayarak analiz etmişlerdir. Zheng ve Zhongxiang (2008) üzerinde açıklık bulunan silindirik kutunun ekranlama etkinliğini tahmin etmek için, açıklık yüzeyi boyunca teğet olan manyetik alandan elde edilen bir sayısal yöntem sunmuşlardır. Mao ve Du (2010) üzerinde açıklık bulunan dikdörtgen koruyucu kutuya ait eşdeğer devre modelini, koruyucu kutunun iki duvarında açıklık olması durumu için hesaplayarak geliştirmişlerdir. İki farklı duvarda, kare veya daire şeklinde açıklıklar için SE analizi gerçekleştirilmiştir. Belkacem ve diğ. (2011) SE analitik formülasyonunu TLM yöntemi ile birleştirerek yeni bir analitik yöntem elde etmişlerdir. Bu yöntemin, Robinson ve dĭg. (1998) tarafından elde edilen analitik yöntemden farkı ise açıklık sayısının birden fazla olduğu, düzlem dalganın polarizasyon ve geliş açılarının değiştirildiği durumlar için de geçerli olmasıdır. Hao ve Li (2014) TLM yöntemini kullanarak yan yüzeylerinde açıklığı olan kutunun ekranlama etkinliğini, TE uyarımda kutu üzerine gönderilen düzlem dalganın geliş ve polarizasyon açılarını değiştirerek analiz etmişlerdir. Ilgar ve diğ. (2015) farklı açıklık şekillerinin, metalik dikdörtgen kutunun ekranlama etkinliğine etkisini analiz etmişlerdir. Oluşturulan nümerik model ile dikdörtgen, kare, beşgen, altıgen ve daire gibi çeşitli açıklıklar için SE değeri hesaplanmıştır. Akiyama ve diğ. (2016) elektrikli araçlardaki evirici için bakır ve polietilen tereftalat (PET) malzemelerinden oluşan çok katmanlı bir yapının elektromanyetik girişimlere (EMI) karşı ekranlama etkinliğini analiz etmişlerdir. Hussain ve diğ. (2020) üzerinde açıklık bulunan dikdörtgen ekranlama kutusunun SE analizini, kutu içerisine metal direkler yerleştirerek gerçekleştirmişlerdir. Yerleştirilen direkler ile SE'nin artırıldığı ve rezonans frekansının ötelendiği görülmüştür.

Elektrikli araçlardaki (EV) yüksek gerilimle çalışan ekipman ve sistemlerden dolayı geleneksel araç elektroniği mimarisi farklı bir boyuta taşınmıştır. Bazı araç uygulamalarında yüksek gerilimin $900 \mathrm{~V}$ seviyelerine çıktığı görülmektedir (Güler ve diğ., 2019). Elektrikli sürüş sistemleri genellikle bir merkezi elektrik motoru ve bunu süren bir eviriciden oluşmaktadır. 
Evirici, içerisinde mikrodenetleyici tabanlı bir kontrol biriminin yanı sıra yüksek anahtarlamaların gerçekleştirildiği IGBT (Insulated Gate Bipolar Transistor) transistörlerini barındıran, elektrikli sürüş sisteminin en önemli güç elektroniği parçasıdır. Bünyesinde barındırdığı hem düşük gerilim hem de yüksek gerilim birimlerinden dolayı EMI'ye karşı oldukça duyarlıdır. Aynı zamanda transistör katındaki yüksek anahtarlamalardan dolayı araç için büyük bir EMI kaynağı oluşturmaktadır.

İdeal olarak, elektronik ekipmanların EMI'ye karşı tam koruma sağlayabilmesi, üzerinde herhangi bir açılık bulunmayan ve yüksek iletkenlikte bir malzemeden oluşan ekranlama kutusuna yerleştirilmesiyle mümkündür. Bununla birlikte, elektronik ekipman koruyucu kutularında güç kabloları, havalandırma deliği, haberleşme kabloları vb. sebeplerden dolayı açıklıklara ihtiyaç vardır. Bu açıklıklar, farklı şekil ve boyutlara sahip olup kutu içerisindeki elektronik devrelere etki edecek şekilde EMI sızıntısına izin vererek ekranlama etkinliğini düşürürler.

EV'de kullanılan elektronik ekipmanların koruyucu kutuları, EMC gerekliliklerini sağlayacak ve de minimum yer kaplayacak şekilde tasarlanmaktadır. Aksi durumda tedarikçi firmalardan temin edilen koruyucu kutuların ilave yer ihtiyacı sebebiyle araç geometrisinin değiștirilmesine kadar gidebilecek çalıșmalar gerekebilmektedir. Bu yüzden, ana sanayi firmaları kutu tasarımlarının belli boyutlarda kalmasını talep etmektedirler. Dolayısıyla, EV'deki elektronik ekipman koruyucu kutuları için SE analizi yapılması ve kutu üzerindeki açıklığın EMC gerekliliklerini sağlayacak şekilde tasarlanması oldukça önemlidir.

$\mathrm{Bu}$ çalışmada, elektrikli sürüş sisteminin EMC açısından kritik ekipmanı olan eviricinin koruyucu kutusuna ilişkin SE analizi gerçekleştirilmiştir. Kutu boyutlarının sabit kaldığı ve üzerindeki açıklık alanının konnektör montajı sebebiyle küçültülemediği durumlarda, ekipman koruyucu kutusunun ekranlama etkinliğini artırabilecek çözüm yollarının üretilmesi amaçlanmıştır. Ayrıca, EV'lerde ileri teknoloji ekipmanların kullanılması ve yüksek kalite veri haberleşmesi (Flexray, Ethernet) gereksinimlerinin artması, literatürde incelenen $0-1 \mathrm{GHz}$ aralığındaki SE çalışmalarını daha geniş bantlara taşımayı gerektirmiştir. Bu çalışma kapsamında, CST Studio Suite programında bir nümerik model oluşturulup $0-2 \mathrm{GHz}$ aralığında SE analizi gerçekleştirilmiştir. Otomotivde kullanılan koruyucu kutu ve açıklık boyutları dikkate alınıp öncelikle Robinson ve diğ. (1998) tarafından oluşturulan analitik model kullanılarak, üzerinde açılık bulunan dikdörtgen koruyucu kutunun SE analizi Matlab programı üzerinde gerçekleştirilmiştir. Sonra, CST Studio Suite programı ile nümerik model tasarlanıp, tutarlılığ analitik yöntem sonuçları ile kıyaslanmıştır. Daha sonra, oluşturulan nümerik modelin analitik modele göre esnekliği sayesinde açıklık alanı aynı kalacak şekilde farklı açıklık geometrileri için SE değişimi 0-2 GHz aralığında analiz edilmiştir. Koruyucu kutu boyutlarının artırılamadığı ve kutu üzerindeki açıklık için alanının küçültülemediği durumlarda SE'yi artıracak tasarımsal çözümler sunulmuştur.

$\mathrm{Bu}$ çalışmanın ikinci bölümünde üzerinde açıklık bulunan dikdörtgen koruyucu kutuların ekranlama etkinliği analitik yöntemle incelenmiştir. Üçüncü bölümde elektronik ekipman koruyucu kutusuna ilişkin nümerik model tasarlanmış ve analitik model ile uyumlu olduğu gösterilmiştir. Farklı açıklık geometrileri için nümerik model ile elde edilen sonuçlar verilmiştir. Dördüncü bölümde ise çalışmaya ilişkin sonuçlardan bahsedilmiştir.

\section{PROBLEMIN FORMÜLASYONU}

Elektronik ekipman koruyucu kutuları üzerinde kablo girişi, konnektör bağlantısı, havalandırma deliği gibi ihtiyaçlardan dolayı açıklık bulunmaktadır. Koruyucu kutu yüzeyindeki açıklık alanının EMC gerekliliklerini sağlayacak şekilde tasarlanması gerekmektedir. Bununla birlikte, konnektör ve kablo girişleri için kullanılacak açıklıkların pratikte kolay uygulanabilecek şekillere sahip olmaları önemlidir. 
Üzerinde dikdörtgen açıklık bulunan koruyucu kutu Şekil 1'de gösterilmiştir. Dikdörtgen kutu mükemmel iletken olarak ele alınmış ve bir düzlem dalga ile uyarılmıştır. P noktası gözlem noktası olarak ifade edilmiştir. Koruyucu kutunun eşdeğer devre modeli ise Robinson ve diğ. (1998) tarafindan yapılan çalışma dikkate alınarak Şekil 2'deki gibi gösterilmiştir. P uzaklığındaki elektrik ekranlama etkinliği, eşdeğer devrede $\mathrm{P}$ noktasındaki gerilimden elde edilmektedir. Yayılan kaynağın etkisi $V_{0}$ gerilimi, $Z_{0}=377 \Omega$ kaynak empedansı ve $k_{0}=2 \pi / \lambda$ yayılma sabiti ile gösterilmektedir.

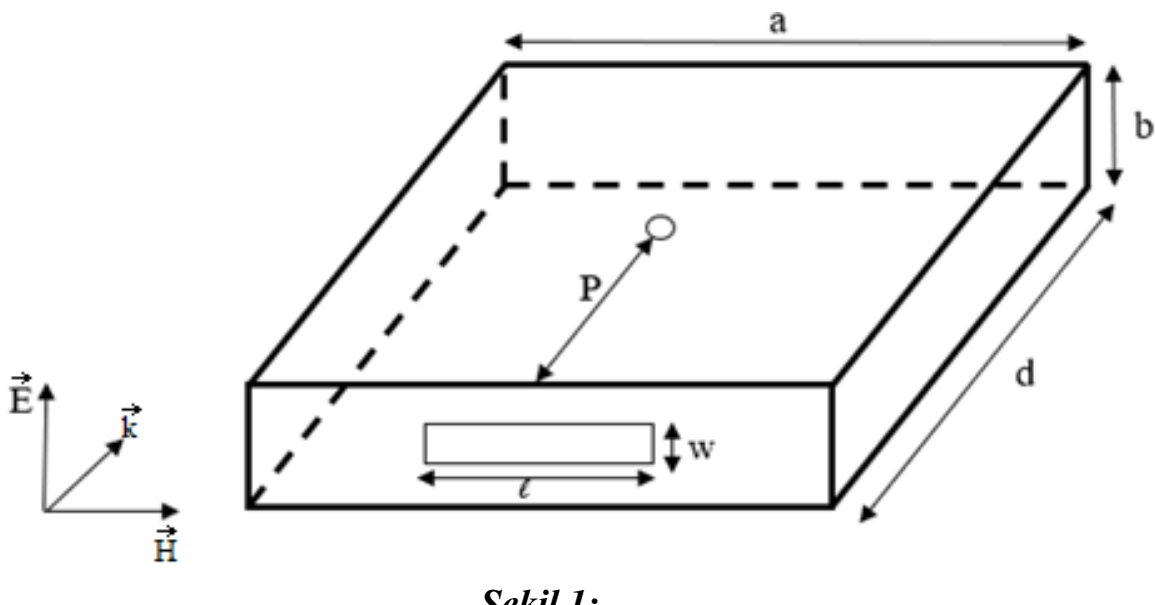

Şekil 1:

Üzerinde açıklık bulunan koruyucu kutu

Koruyucu kutuyla ilgili olarak, kısa devre olan dalga kılavuzuna ait karakteristik empedans $Z_{g}$ ve yayılım sabiti $k_{g}$ ile gösterilmektedir. Öncelikle açıklık için eşdeğer bir empedans bulunup, ardından $\mathrm{P}$ noktasındaki gerilimi ve empedansı hesaplamak için iletim hattı teorisinden faydalanılmıştır.

Analitik yöntemde açılık, her iki uçta kısa devre olan bir düzlemsel şerit iletim hattının uzunluğu olarak temsil edilir. Bu durum sadece koruyucu kutunun ön yüzündeki iletim hattı akımlarının dikkate alınması gerektiği anlamına gelir. Açıklığa ait iletim hattı karakteristik empedans1, Gupta ve diğ. (1979) tarafından belirlenen denklem (1) takip edilerek elde edilmiştir.

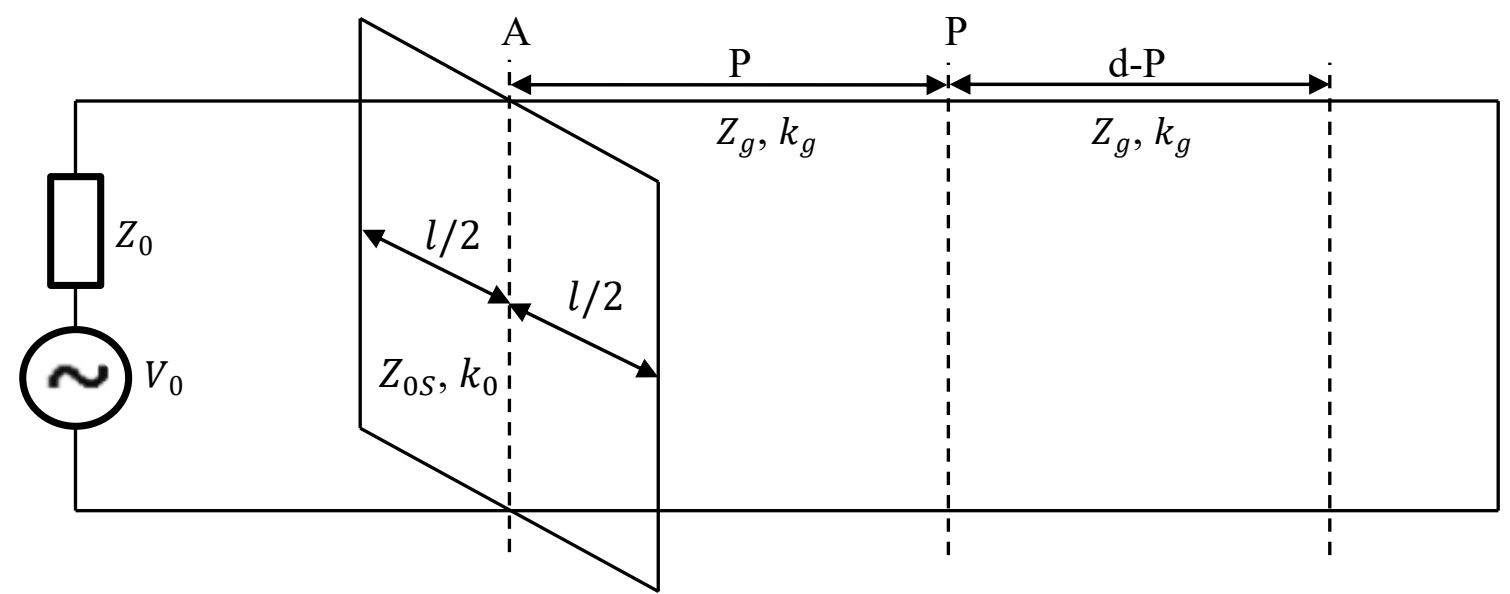

Şekil 2:

Üzerinde açıklık bulunan dikdörtgen koruyucu kutunun eşdeğer devresi

$$
Z_{0 S}=120 \pi^{2}\left[\ln \left(2 \frac{1+\sqrt[4]{1-\left(w_{e} / b\right)^{2}}}{1-\sqrt[4]{1-\left(w_{e} / b\right)^{2}}}\right)\right]^{-1}
$$


A noktasındaki $Z_{a p}$ açıklık empedansı ise, açıklığın merkezinden $l / 2$ mesafede yer alan uçlarına kısa devre uygulanarak

$$
Z_{a p}=\frac{1}{2} \frac{l}{a} j Z_{0 S} \tan \frac{k_{0} l}{2}
$$

olarak ifade edilmiştir (Robinson ve diğ., 1998).

\subsection{Ekranlama Etkinliği}

Thevenin teoreminden yola çıkarak $Z_{0}, V_{0}$ ve $Z_{a p}$ bileşiminden $V_{1}$ eşdeğer gerilimi ve $Z_{1}$ kaynak empedans 1

$$
\begin{aligned}
& V_{1}=V_{0}\left(\frac{Z_{a p}}{Z_{a p}+Z_{0}}\right) \\
& Z_{1}=V_{0}\left(\frac{Z_{a p} Z_{0}}{Z_{a p}+Z_{0}}\right)
\end{aligned}
$$

olarak elde edilmiştir (Robinson ve diğ., 1998). TE ${ }_{10}$ modu yayılma için, dalga k1lavuzu karakteristik empedansı ve yayılma sabiti ise

$$
\begin{aligned}
& Z_{g}=Z_{0} / \sqrt{1-(\lambda / 2 a)^{2}} \\
& k_{g}=k_{0} / \sqrt{1-(\lambda / 2 a)^{2}}
\end{aligned}
$$

olarak ifade edilir (Robinson ve diğ., 1998). $V_{1}, Z_{1}$ ve dalga kılavuzu sonu P noktasına kısa devre dönüşümü uygulandığında eşdeğer gerilim, kaynak empedansı ve yük empedansı da sirasıyla aşağıdaki gibi elde edilmiştir (Robinson ve diğ., 1998).

$$
\begin{gathered}
V_{2}=\frac{V_{1}}{\cos _{g} p+j\left(Z_{1} / Z_{g}\right) \sin _{g} p} \\
Z_{2}=\frac{Z_{1}+j Z_{g} \operatorname{tank}_{g} p}{1+j\left(Z_{1} / Z_{g}\right) \operatorname{tank}_{g} p} \\
Z_{3}=j Z_{g} \operatorname{tank}_{g}(d-p)
\end{gathered}
$$

Elektronik ekipman koruyucu kutusunun olduğu hesaplamada $\mathrm{P}$ noktasındaki gerilim aşağıdaki gibi ifade edilmiştir (Robinson ve diğ., 1998).

$$
V_{p}=V_{2}\left(\frac{Z_{3}}{Z_{3}+Z_{2}}\right)
$$

Koruyucu kutunun olmadığ 1 durumda ise $\mathrm{P}$ noktasındaki yük empedansı $Z_{0}$ 'a eşit olduğundan $\mathrm{P}$ noktasındaki gerilim $V_{p}^{\prime}=V_{0} / 2$ 'dir. Bu durumda elektrik ekranlama etkinliği 


$$
S_{E}=-20 \log _{10}\left|\frac{v_{p}}{v_{p}^{\prime}}\right|=-20 \log _{10}\left|\frac{2 v_{p}}{v_{0}}\right|
$$

olarak ifade edilmiştir (Robinson ve diğ., 1998).

\subsection{Ekranlama Etkinliği Hesaplamaları}

Üzerinde dikdörtgen açıklık bulunan elektronik ekipman koruyucu kutusu için gerçekleştirilen hesaplamalarda kutu ve açıklık boyutları değişiminin SE'ye etkisi incelenmiştir. Şekil 3'te açıklık boyutları $l, w$ değerlerindeki değişiminin koruyucu kutunun ekranlama etkinliği üzerindeki etkisi gösterilmiştir. Açıklık alanı küçüldükçe, koruyucu kutu içerisine giren elektrik alanın genliği azalmaktadır. Bu eğilim, daha küçük açıklık boyutu ile koruyucu kutunun ekranlama etkinliğinin büyük ölçüde artırıldığını göstermektedir. Bununla birlikte, A2'den A3'e olan açıklık alanı artışına rağmen SE'nin 5,77 dB iyileştiği elde edilmiştir. Bu durum, $w$ değerindeki değişimin SE üzerinde, $l$ değerindeki değişimlere göre daha baskın olduğunu göstermektedir. İlerleyen dalganın elektrik alan bileşeni açıklık eni $w$ ile örtüştüğünden, $w$ değeri artıkça daha büyük genlikli elektrik alan açıklıktan içeri girmektedir.

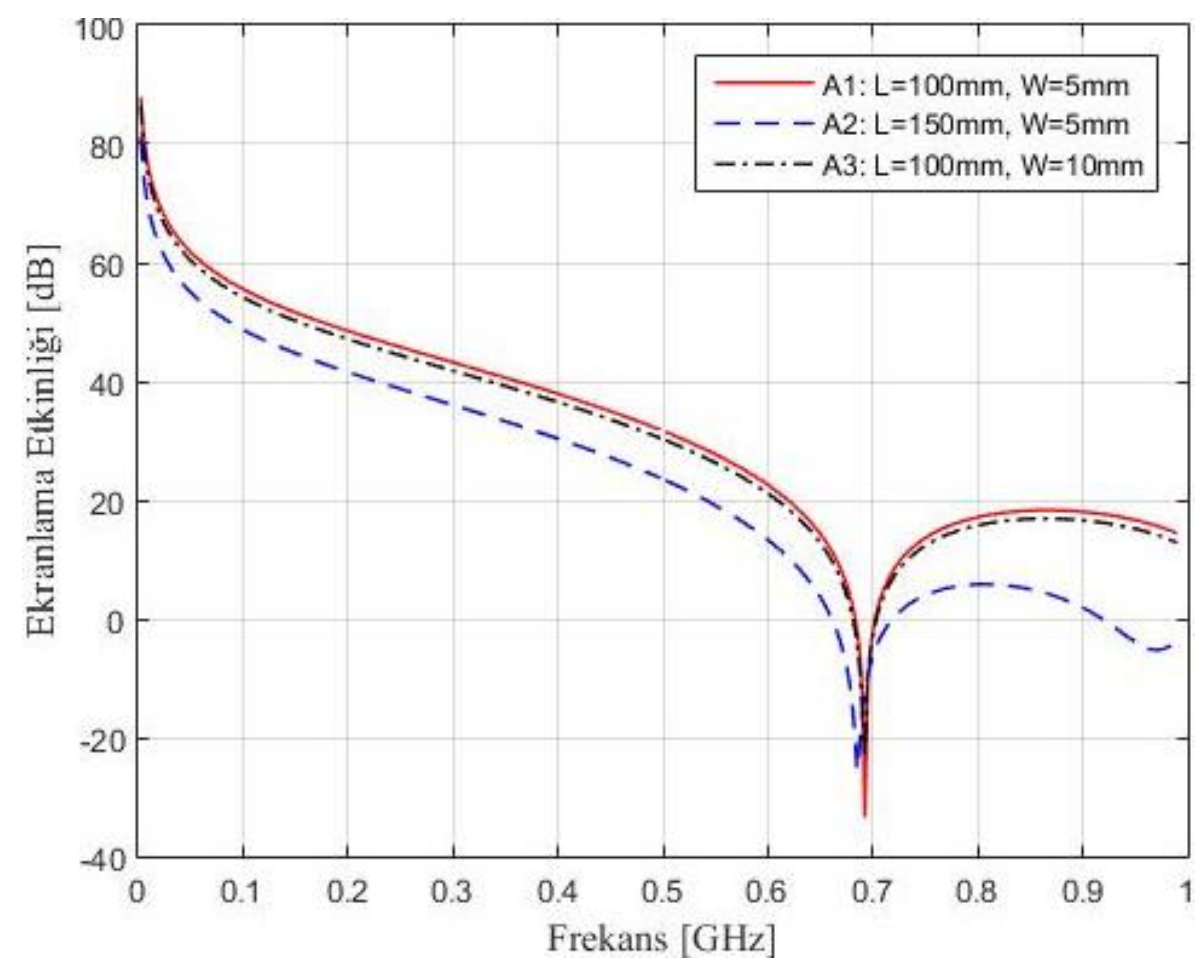

Şekil 3:

Açıklık boyutunun ekranlama etkinliğine etkisi (kutu boyutu: 300x160x310 mm) 


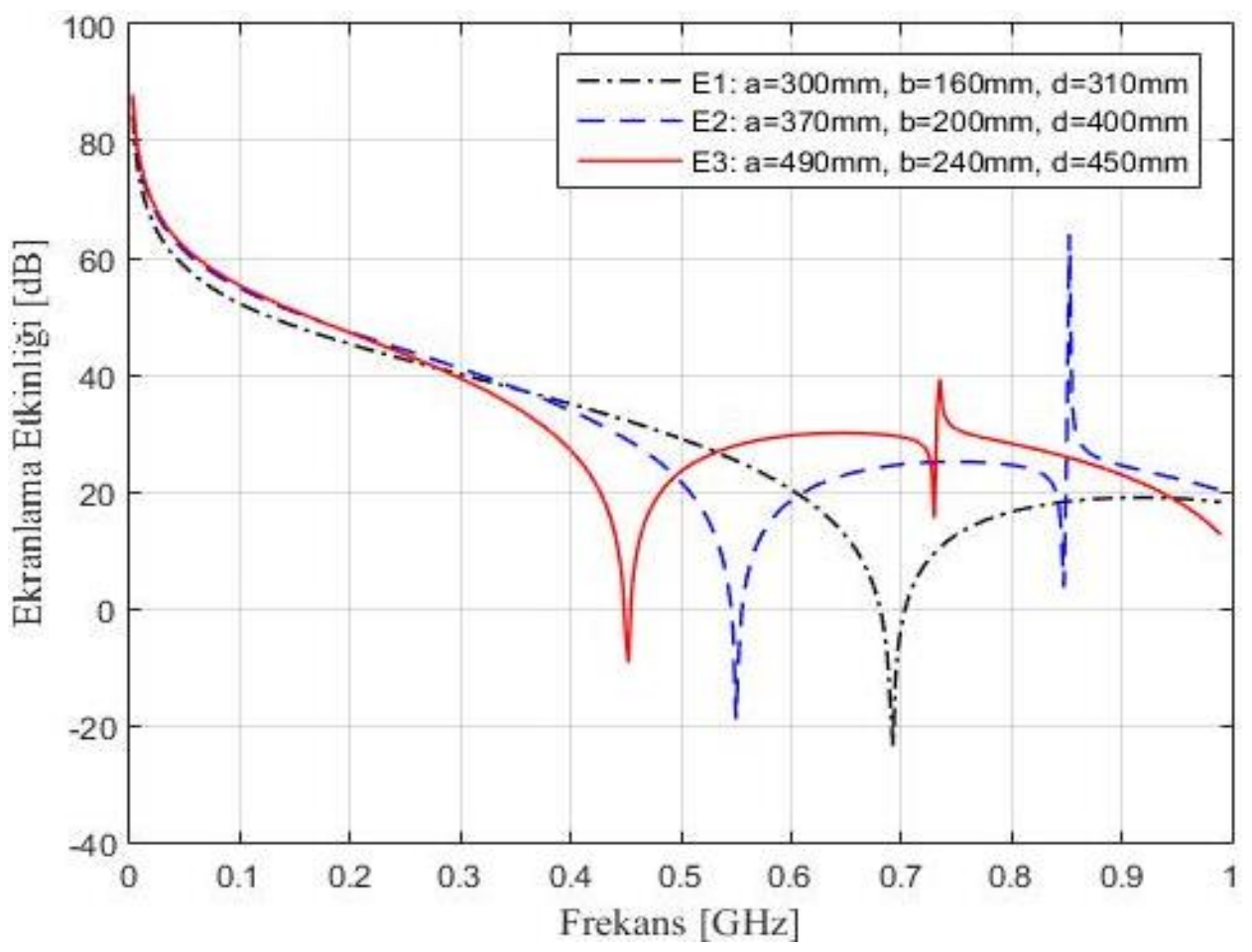

Şekil 4:

Kutu boyutunun ekranlama etkinliği üzerine etkisi (açıklı boyutu: $l=100 \mathrm{~mm}, w=10 \mathrm{~mm}$ )

Şekil 4'te $l=100 \mathrm{~mm}$ ve $w=10 \mathrm{~mm}$ boyutlarında bir açıklığa sahip üç farklı boyutta kutu için ekranlama etkinliği değerleri gösterilmiştir. Elde edilen sonuçlara göre SE'nin büyük boyutlara sahip kutu için daha iyi olduğu görülmektedir. Koruyucu kutunun rezonans frekansı aşağıdaki denklem ile ifade edilebilir (Ilgar ve diğ., 2015).

$$
f_{m n p}=\frac{1}{2 \sqrt{\mu_{0} \varepsilon_{0}}} \sqrt{\left(\frac{m}{a}\right)^{2}+\left(\frac{n}{b}\right)^{2}+\left(\frac{p}{d}\right)^{2}}
$$

Burada $m, n$ ve $p$ tam sayı olup $m=n \neq 0$ 'dır. $a, b$ ve $d$ ise kutu boyutlarıdır. $\mu_{0}$ ve $\varepsilon_{0}$ ise sırasıyla kutu içindeki serbest uzayın manyetik ve elektrik geçirgenlikleridir. $\mathrm{TE}_{101}$ dominant modu için $m=1, n=0$ ve $p=1$ olup, denklem (12) ile elde edilen frekans değerlerinin Şekil 4'teki rezonans frekanslarıyla uyumlu olduğu görülmektedir. Koruyucu kutular E1, E2 ve E3 için $\mathrm{TE}_{101}$ modu rezonans frekansları sırasıyla $692 \mathrm{MHz}, 550 \mathrm{MHz}$ ve $452 \mathrm{MHz}$ 'dir. Beklendiği gibi aynı açıklık boyutlarına sahip kutular için kutu boyutu büyüdükçe rezonansın daha düşük frekanslarda başladığı görülmektedir. E2 ve E3 kutuları için $0-1 \mathrm{GHz}$ aralığında ikinci rezonansların meydana geldiği görülmektedir. Birinci rezonanslara göre daha düşük seviyedeki bu rezonanslar $\mathrm{TE}_{011}$ moduyla ilişkilidir. $\mathrm{E} 2 \mathrm{ve} \mathrm{E} 3$ kutuları için $\mathrm{TE}_{011}$ modu rezonans frekansları sirayla $838 \mathrm{MHz}, 710 \mathrm{MHz}$ 'dir.

Şekil 5'te toplam açıklık alanı aynı kalırken açıklık sayısının artırılmasının SE üzerindeki etkisi incelenmiştir. Elde edilen sonuçlara göre aynı alan için açıklık sayısı artırıldığında SE'nin de artığı görülmektedir. Bir büyük açıklık kullanmak yerine aynı alana sahip küçük açıklıkların yerleştirilmesinin SE üzerinde olumlu etkisi olduğu görülmektedir. 


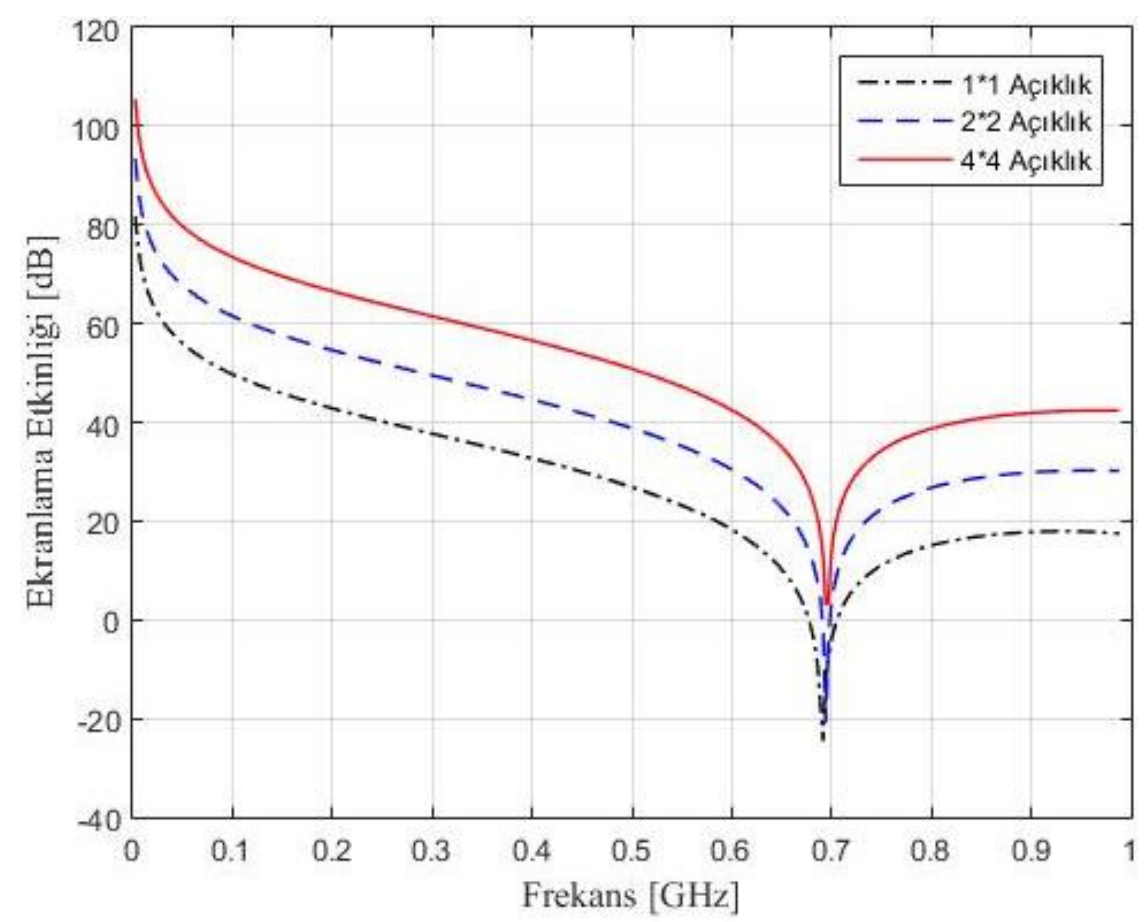

Şekil 5:

$80 \times 80 \mathrm{~mm}^{2}$ bir alanda birden fazla açılklk olması durumu (kutu boyutu: $300 \times 160 \times 310 \mathrm{~mm}$ )

\section{NÜMERIKK SONUÇLAR}

Otomotivde elektronik ekipman koruyucu kutuları EMC gerekliliklerini sağlayacak ve de minimum yer kaplayacak şekilde tasarlanmaktadır. Aksi durumda tedarikçi firmalardan temin edilen elektronik ekipman koruyucu kutularının ilave yer ihtiyacı sebebiyle araç geometrisinin değiştirilmesine kadar gidebilecek çalışmalar gerekebilmektedir. Bu yüzden, ana sanayi firmaları koruyucu kutu tasarımlarının belli boyutlarda kalmasını talep etmektedirler.

Şekil 4'teki sonuca göre açıklık sabit kalıp kutu boyutu artırıldığında koruyucu kutunun ekranlama etkinliğinde iyileşmeler olduğu gösterilmiştir. Dolayısıyla, tedarikçi firmanın büyük kutu kullanmasının SE üzerinde olumlu etkileri bulunmaktadır. Diğer taraftan ise EMC gerekliliklerini yerine getirirken ana firmalardan gelen koruyucu kutu boyutlarındaki kısıtlamalar zorlayıcı olabilmektedir. Bu çalışmada, kutu boyutlarının sabit kaldığı durumlarda, EV'deki elektronik ekipman koruyucu kutusunun ekranlama etkinliğini artırabilecek yollar araştırılmıştır.

Otomotivde kullanılan elektronik ekipman koruyucu kutularında konnektör bağlantıları için sıklıkla dikdörtgen, daire ve üçgen şeklinde açıklıklar kullanılmaktadır. Kutu boyutunun sabit kaldığı ve açıklık alanının konnektör bağlantısından dolayı küçültülemediği durumlarda SE’nin $30 \mathrm{~dB}$ üzerinde olmasını sağlayacak tasarımsal çözümler gerekmektedir.

Nümerik yöntem için CST Studio Suite programında, FEM tabanlı frekans domeni çözücüsü kullanılmıştır. 5526 adet hücreden (tetrahedron) oluşan bir nümerik model tasarlanmış olup analitik yöntemle uyumluluğu simülasyonla gösterilmiştir. Elektronik ekipman koruyucu kutusunun boyutları $a=300 \mathrm{~mm}, b=160 \mathrm{~mm}, d=310 \mathrm{~mm}$, ön yüzeyinin merkezine yerleştirilmiş açıklığın boyutları ise $l=100 \mathrm{~mm}, w=10 \mathrm{~mm}$ olarak tasarlanmıştır. Kutunun duvar kalınlığ $t=2,5 \mathrm{~mm}$, kutu malzemesi alüminyum olarak alınmıştır. Nümerik modelde $\mathrm{p}$ gözlem noktası koruyucu kutunun merkezine yerleştirilmiş olup ekranlama etkinliği değerini elde etmek için aşağıdaki denklemde belirtildiği gibi kutu varken ve kutu yokken o noktada hesaplanan değerler kullanılmıştır (Bahadorzadeh ve Moghaddasi, 2006). 


$$
S_{E}=20 \log _{10}\left|\frac{E_{\text {kutu yok }}(p)}{E_{\text {kutu var }}(p)}\right|
$$

Şekil 6'da nümerik model ve TE uyarımda uygulanan Gauss geçici düzlem dalgası gösterilmiştir. Gauss düzlem dalgası, pozitif dikey eksen boyunca genliği zaman içinde basamak fonksiyonu olarak değişen elektrik alan polarizasyonuna sahiptir. Elektrik alan dağılımları, koruyucu kutunun merkez noktasında hesaplanmıștır. Problem uzayında koruyucu kutu duvarları için elektrik iletkenliği $\sigma=3,56 \times 10^{7} \mathrm{~S} / \mathrm{m}$, kutu içi ve dış1 için ise $\sigma=0 \mathrm{~S} / \mathrm{m}$ serbest uzay olarak tanımlanmıştır.

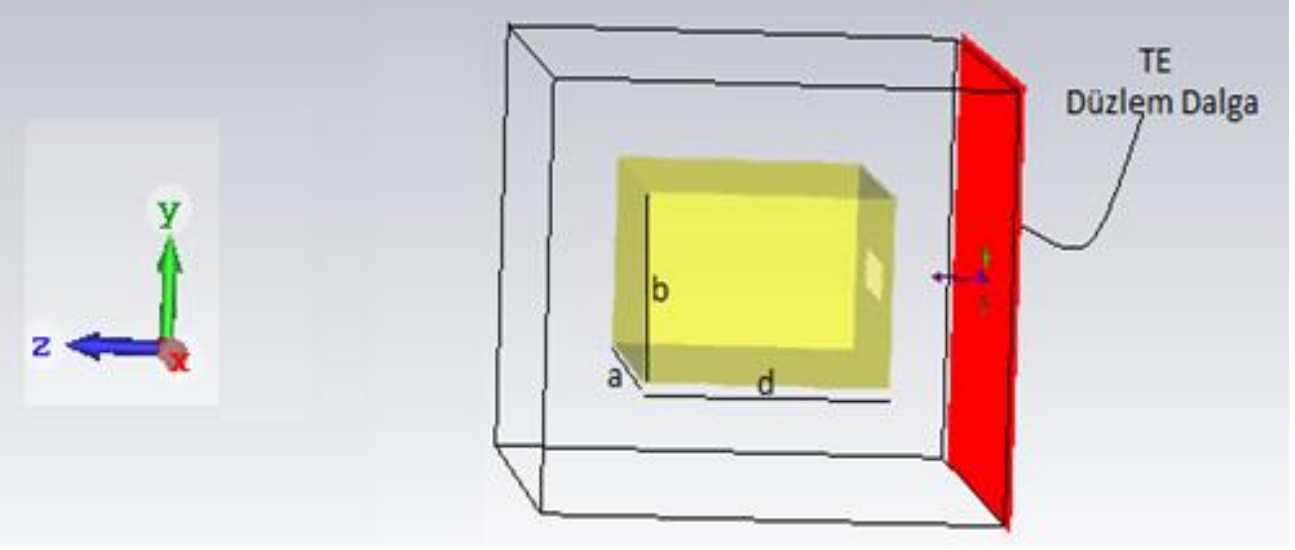

Şekil 6:

Nümerik model ve TE uyarımda uygulanan düzlem dalga

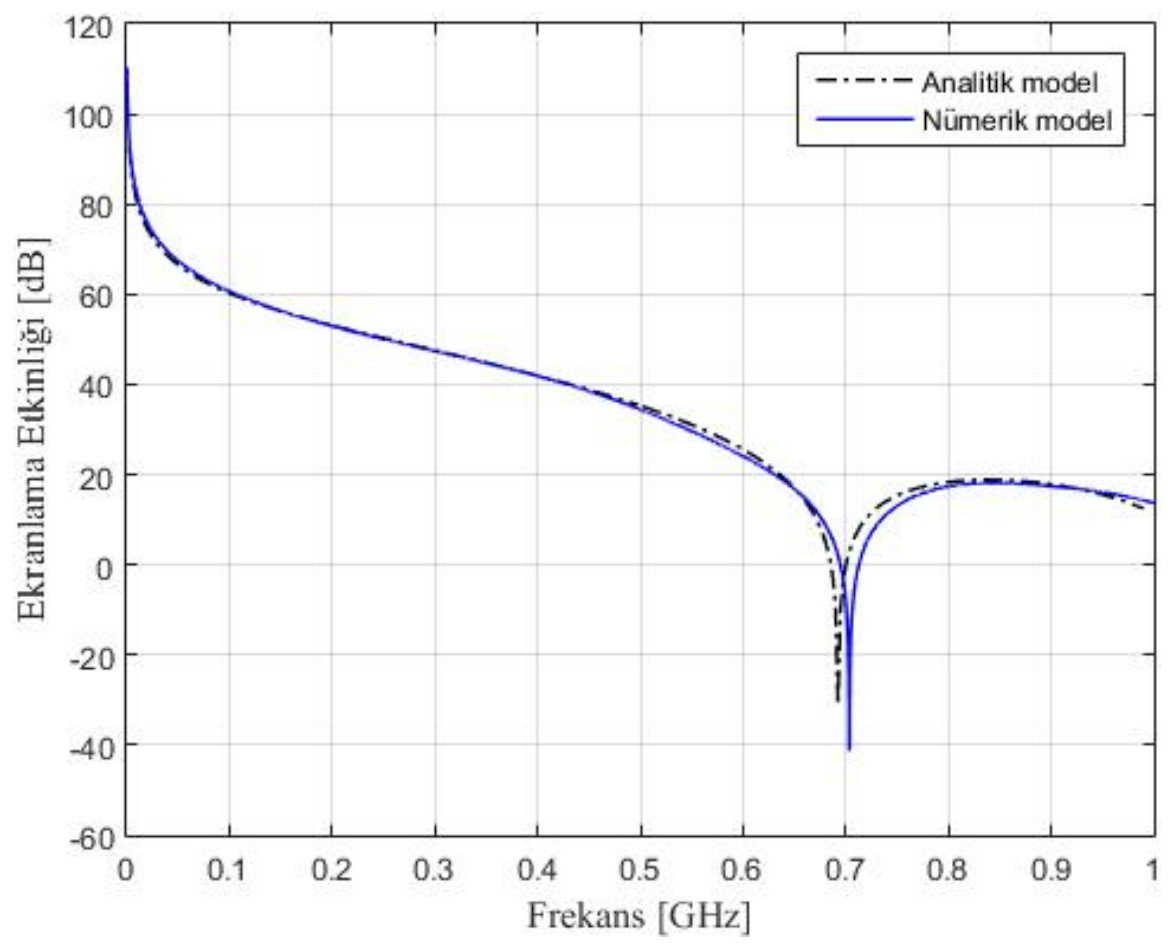

Şekil 7:

Analitik model ile nümerik modelin karşılaştırılması 
Şekil 7'de 0-1 GHz frekans aralığında analitik model ile nümerik model sonuçları gösterilmiştir. Ekranlama etkinliği değerlerindeki fark $0,22 \mathrm{~dB}$ olarak elde edilmiştir. Nümerik modelin analitik model ile uyumlu olduğu görülmektedir.

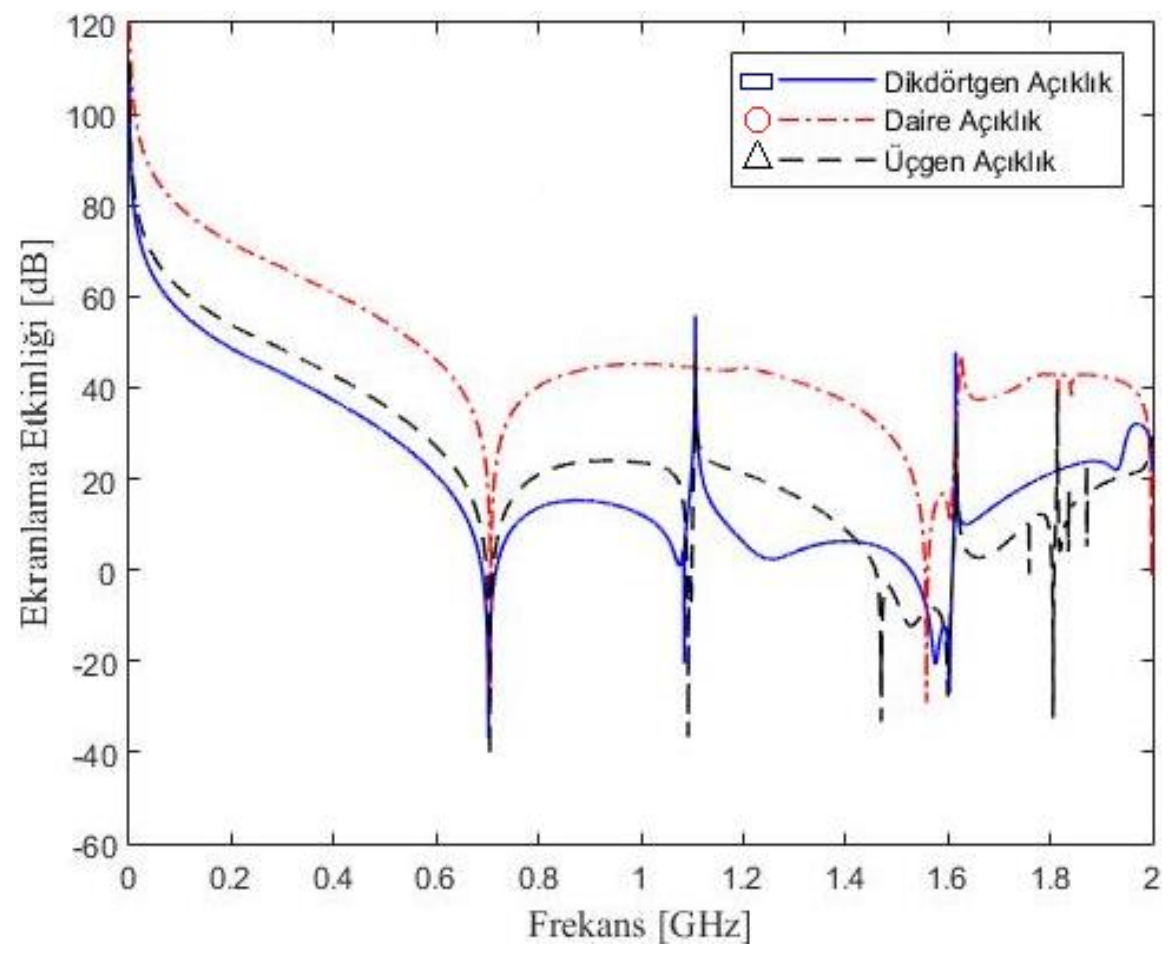

Şekil 8:

$1000 \mathrm{~mm}^{2}$ 'lik açılklı̆̆ı farkl geometrilerde olması halinde ekranlama etkinliğinin değişimi

Şekil 8'de nümerik model için açıklık alanı $1000 \mathrm{~mm}^{2}$ kalacak şekilde açıklı̆̆ın farklı geometrilerde olması durumu 0-2 GHz aralığında incelenmiştir. Tablo 1 ve Tablo 2'de elde edilen farklı örnekleme frekanslarındaki SE değerleri karşılaştırılmıştır. Daire şeklinde açıklık olması durumunda en iyi SE sonucu elde edilmiştir. Dikdörtgen açıklıktaki en kötü durum olan 1,2 GHz'deki SE değeri, daire açıklık kullanımında 38,23 dB artırılmıştır. Bu durum, elektronik ekipman koruyucu kutusunun ekranlama etkinliğinin $\geq 30 \mathrm{~dB}$ olmasını sağlayarak yeterli bir koruma seviyesine çıkmasını sağlamaktadır. Aynı alana sahip farklı açıklık geometrileriyle yapılan SE analizlerinde, SE’nin en zayıf olduğu durumun üçgen geometri ile elde edilmesi, açıklık eninin en büyük değere sahip olması ile ilgilidir. Şekil 3 'te gösterilen açıklık boyutlarıyla SE'nin değişimine göre, $w$ değeri artıkça daha büyük genlikli elektrik alan açılıktan içeri sizmaktadır.

Tablo 1. Açıklık geometrisinin SE'ye etkisi (0-800 MHz)

\begin{tabular}{|l|c|c|c|c|}
\hline Açıklık Şekli & $\mathbf{2 0 0} \mathbf{~ M H z}$ & $\mathbf{4 0 0} \mathbf{~ M H z}$ & $\mathbf{6 0 0} \mathbf{~ M H z}$ & $\mathbf{8 0 0} \mathbf{~ M H z}$ \\
\hline Dikdörtgen & $52,95 \mathrm{~dB}$ & $41,86 \mathrm{~dB}$ & $24 \mathrm{~dB}$ & $17,36 \mathrm{~dB}$ \\
\hline Üçgen & $+6,24 \mathrm{~dB}$ & $+6,92 \mathrm{~dB}$ & $+8,13 \mathrm{~dB}$ & $+9,77 \mathrm{~dB}$ \\
\hline Daire & $+19,35 \mathrm{~dB}$ & $+19,96 \mathrm{~dB}$ & $+21,69 \mathrm{~dB}$ & $+24,13 \mathrm{~dB}$ \\
\hline
\end{tabular}


Tablo 2. Açıklık geometrisinin SE'ye etkisi (1-2 GHz)

\begin{tabular}{|l|c|c|c|c|}
\hline Açıklık Şekli & $\mathbf{1 ~ G H z}$ & $\mathbf{1 , 2} \mathbf{~ G H z}$ & $\mathbf{1 , 4} \mathbf{~ G H z}$ & $\mathbf{1 , 8} \mathbf{~ G H z}$ \\
\hline Dikdörtgen & $12,11 \mathrm{~dB}$ & $6,03 \mathrm{~dB}$ & $6,3 \mathrm{~dB}$ & $7,39 \mathrm{~dB}$ \\
\hline Üçgen & $+11,32 \mathrm{~dB}$ & $+15,11 \mathrm{~dB}$ & $+2,52 \mathrm{~dB}$ & $+13,76 \mathrm{~dB}$ \\
\hline Daire & $+33,08 \mathrm{~dB}$ & $+38,23 \mathrm{~dB}$ & $+30,71 \mathrm{~dB}$ & $+35,52 \mathrm{~dB}$ \\
\hline
\end{tabular}

Şekil 8'de 1 GHz'in altındaki frekanslarda her üç açıklık geometrisi için $\mathrm{TE}_{101}$ modu rezonansı $700 \mathrm{MHz}$ 'de oluşmaktadır. Bu durum, açıklık geometrisinin koruyucu kutu rezonansını $1 \mathrm{GHz}$ 'in altında etkilemediğini göstermektedir.

$1 \mathrm{GHz}$ 'in üzerinde ise açıklı geometrisine göre farklı frekans değerlerinde birden fazla rezonans meydana gelebilmektedir. Şekil 8'deki simülasyon sonuçlarına göre dikdörtgen ve üçgen açıklık olması durumlarında $\mathrm{TE}_{201}$ modu rezonans frekansı $1,11 \mathrm{GHz}$ 'de meydana gelmektedir. Üçgen açıklık olması durumunda, $\mathrm{TE}_{211}$ modu için rezonans $1,47 \mathrm{GHz}$ 'de oluşmaktadır. Daire açıklık olması durumunda ise, $\mathrm{TE}_{103}$ modu için rezonans $1,55 \mathrm{GHz}$ 'de oluşmaktadır. Üçgen ve dikdörtgen açıklık olması durumlarında, bir diğer rezonansın $\mathrm{TE}_{212}$ modu için 1,6 GHz'de meydana geldiği görülmektedir. Son olarak, üçgen açıklık için $\mathrm{TE}_{311}$ modu rezonans frekansının 1,8 GHz'de olduğu görülmektedir.

Denklem (12) kullanılarak gerçekleştirilen kutu rezonans frekansı hesaplamaları ile Şekil 8'deki simülasyon sonuçlarının karşılaştırılması Tablo 3'te gösterilmiştir. Farklı açıklık şekillerine göre kutu rezonanslarının varlığı + ile belirtilmiştir. $\mathrm{TE}_{101}$ ve $\mathrm{TE}_{201}$ modları için hesaplamalar ile simülasyondan elde edilen sonuçlar uyumlu olduğundan $1 \mathrm{GHz}$ 'in altındaki rezonanslar Tablo 3'te belirtilmemiştir. $1 \mathrm{GHz}$ 'in üzerindeki hesaplamalarda ise kutu rezonans frekanslarında kaymalar görülmektedir. $\mathrm{Bu}$ fark, açılık-koruyucu kutu (rezonatör) etkileşiminden kaynaklanmaktadır.

Tablo 3. Rezonans frekansı hesaplamaları ile simülasyon sonuçlarının karşılaştırılması

\begin{tabular}{|c|c|c|c|c|c|c|c|c|}
\hline \multirow{3}{*}{$\begin{array}{l}\text { Açıklık } \\
\text { Şekli }\end{array}$} & \multicolumn{2}{|c|}{$\mathbf{T E}_{211}$} & \multicolumn{2}{|c|}{$\mathrm{TE}_{103}$} & \multicolumn{2}{|l|}{$\mathbf{T E}_{212}$} & \multicolumn{2}{|l|}{$\mathbf{T E}_{311}$} \\
\hline & Hesaplama & Fark & Hesaplama & Fark & Hesaplama & Fark & Hesaplama & Fark \\
\hline & $1,453 \mathrm{GHz}$ & 0,017 & $1,535 \mathrm{GHz}$ & 0,015 & $1,67 \mathrm{GHz}$ & 0,07 & $1,83 \mathrm{GHz}$ & 0,03 \\
\hline Dikdörtgen & & & & & + & & & \\
\hline Üçgen & + & & & & + & & + & \\
\hline Daire & & & + & & & & & \\
\hline
\end{tabular}

\section{SONUÇLAR}

Elektrikli araçlar, içten yanmalı motora sahip araçlara göre daha karmaşık ve birbirine etkisi daha fazla olan elektronik ekipman ve sistemleri bünyesinde barındırmaktadır. $12 \mathrm{~V}$ batarya ünitesiyle çalışan sistemler ile yüksek gerilimli batarya tarafindan beslenen ekipman ve sistemlerin bir arada uyum içinde çalışabilmesi için dikkat edilmesi gereken önemli konulardan biri de elektromanyetik uyumluluktur.

$\mathrm{Bu}$ çalışmada elektrikli araçlarda sıklıkla görülen EMC problemlerinden biri olan elektronik ekipman koruyucu kutularındaki ekranlama problemi incelenmiştir. Elde edilen analitik sonuçlara 
göre kutu boyutu artıkça SE'nin artığı görülmektedir. Kutu boyutu sabit kalıp üzerindeki açıklık alanının artması ise SE'yi zayıflatmaktadır. Elektronik ekipman koruyucu kutularında büyük açıklıklar yerine aynı toplam alana sahip küçük açıkların yerleştirilmesi ekranlama etkinliğini iyileştirmektedir.

Elektrikli araçlarda kullanılan elektronik ekipman koruyucu kutularının, minimum yer kaplayacak şekilde boyutlandırılması ve aynı zamanda EMC gerekliliklerini yerine getirecek SE değerlerini sağlaması önemlidir. Bu çalışmada, kutu boyutlarının sabit kaldığı ve üzerindeki açıklı̆̆n konnektör montajı için belli bir alana sahip olması gerektiği durumda, elektronik ekipman koruyucu kutusunun ekranlama etkinliğini artırabilecek yollar araştırılmıştır. EV'lerde yüksek kalite veri haberleşmesi gereksinimlerinin artmasından dolayı çalışmalar, 0-2 GHz aralığında farklı açıklık geometrileriyle gerçekleştirilmiştir. Aynı açıklık alanı için, açıklığın dikdörtgen, üçgen ve daire şekillerinde olması durumlarında gerçekleştirilen SE analizlerine göre, açıklığın daire şeklinde olması dikdörtgen şeklinde elde edilen sonuçlara kıyasla SE üzerinde minimum 19,35 dB iyileştirme sağlamıştır. Ayrıca, $1 \mathrm{GHz}$ üzerinde açıklık geometrisine bağlı olarak farklı frekans değerlerinde rezonansların meydana geldiği ve açıklık-koruyucu kutu etkileşiminden kaynaklı olarak bazı rezonans frekanslarında kaymaların olduğu görülmüştür. Oluşan bu rezonanslar, koruyucu kutu içerisinde yer alan elektronik devrelerin fonksiyonelliğini etkilemektedir. Koruyucu kutu üzerinde, daire açıklık olması durumunda rezonansların daha az meydana geldiği görülmektedir.

\section{TEŞEKKÜR}

CST Studio Suite programındaki katkılarından dolayı Tunç Murat İlgar’a teşekkür ederiz.

\section{KAYNAKLAR}

1. Akiyama, T. ve diğ. (2016) Shielding effectiveness of multi-layered $\mathrm{Cu}$ and PET thin films from electromagnetic interference, IEEE International Instrumentation and Measurement Technology Conference, IEEE, Taipei. doi:10.1109/I2MTC.2016.7520499

2. Bahadorzadeh, M. ve Moghaddasi M. N. (2006) Improving shielding effectiveness of a rectangular metallic enclosure with aperture by using extra shielding wall, 12th International Symposium on Antenna Technology and Applied Electromagnetics and Canadian Radio Sciences Conference, IEEE, Montreal.

3. Belkacem, F. T. ve diğ. (2011) Combined model for shielding effectiveness estimation of a metallic enclosure with apertures, Science, Measurement \& Technology, 5(3), 88-95. doi:10.1049/iet-smt.2010.0040

4. Belokour, I. ve diğ. (2000) Shielding effectiveness estimation of enclosures with apertures, International Symposium on Electromagnetic Compatibility -(Cat. No. O0CH37016 ), IEEE, Washington. doi: 10.1109/ISEMC.2000.874734

5. Dan, S. ve diğ. (2007) Determination of Shielding Effectiveness of Multilayer Shield by Making Use of Transmission Line Theory, 7th International Symposium on Electromagnetic Compatibility and Electromagnetic Ecology, IEEE, Saint-Petersburg. doi:10.1109/EMCECO.2007.4371656

6. Dassault Systemes Simulia (2019) CST Studio Suite (Sürüm: 2019 Research Base Pack). Tedarik edilebileceği adres: https://www.3ds.com/products-services/simulia/products/cststudio-suite/

7. Fan, Y. ve diğ. (2003) Analysis on shielding effectiveness of metallic enclosures with slot, Asia-Pacific Conference on Environmental Electromagnetics, IEEE, Hangzhou. doi:10.1109/CEEM.2003.238480 
8. Feng, C. ve diğ. (2005) A hybrid FD-MoM technique for predicting shielding effectiveness of metallic enclosures with apertures, , IEEE Transactions on Electromagnetic Compatibility, 47(3), 456-462. doi:10.1109/TEMC.2005.851726

9. Gupta, K.C. (1979) Microstrip Lines and Slotlines, Artech House, Norwood.

10. Güler, S. (2007) Elektromanyetik Uyumluluk Tekniklerinde Elektromanyetik Işımanın Modellenmesi, Doktora Tezi, U.Ü. Fen Bilimleri Enstitüsü, Bursa.

11. Güler, S. ve diğ. (2019) EMC Design for Battery Electric Vehicle (BEV) Propulsion System, 11th International Conference on Electrical and Electronics Engineering (ELECO), IEEE, Bursa. 286-289. doi:10.23919/ELECO47770.2019.8990410

12. Hao, C. ve Li D. (2014) Simplified model of shielding effectiveness of a cavity with apertures on different sides, IEEE Transactions on Electromagnetic Compatibility, 56(2), 335-342. doi: 10.1109/TEMC.2013.2280152

13. Hussain $T$. ve diğg. (2020) Improved shielding effectiveness of enclosures using symmetrically placed metallic posts, 17th International Bhurban Conference on Applied Sciences and Technology (IBCAST), IEEE, 679-685. doi: 10.1109/IBCAST47879.2020.9044504

14. Ilgar T. ve diğ. (2015) Shielding effectiveness for metallic enclosures with various aperture shapes, 1st URSI Atlantic Radio Science Conference (URSI AT-RASC), IEEE, Las Palmas. doi: 10.1109/URSI-AT-RASC.2015.7303047

15. Mao X. ve Du P.A. (2010) An improved model of Robinson equivalent circuit analytical model, Science China Technological Sciences, 53(7), 1993-1999. doi: 10.1007/s11431-0093244-9

16. Mathworks Software (2019) Matlab (Sürüm: R2019b). Tedarik edilebileceği adres: http://www.figes.com.tr/

17. Robinson, M.P. ve diğ. (1998) Analytical formulation for the shielding effectiveness of enclosures with apertures, IEEE Transactions on Electromagnetic Compatibility, 40(3), 240248. doi: 10.1109/15.709422

18. Yenikaya, S. ve Akman, A. (2009) Hybrid MoM/FEM modelling of loaded enclosure with aperture in EMC problems, International Journal of RF and MW Computer Aided Journal, 19(2), 204-210. doi:10.1002/mmce.20341

19. Zheng B. ve Zhongxiang S. (2008) Shielding effectiveness of cylindrical enclosures with rectangular apertures, Asia-Pacific Symposium on Electromagnetic Compatibility and 19th Internaltional Zurich Symposium on Electromagnetic Compatibility, IEEE, Singapore. 710713. doi: 10.1109/APEMC.2008.4559974 
